following remarks reference will be made only to the acquired form.

While doing temporary work in a Yorkshire district some three or four years ago I noticed many cases among infants, but the fact that it was advisable to make any special mention of it did not then occur, but quite recently while on temporary duty in a district in South Wales, I again observed the frequency of the complaint, and in a week saw eight to ten cases in a town of some 70,000 inhabitants. That such a number should be seen in a few days, while examining the abdomen of infants in various illnesses must indicate that the condition is exceedingly prevalent in this centre. I have also recently noticed its prevalence in a London district. On considering the cause I may say that I always make the inquiry as to who attended the mother at the birth of the child, and I can only recall an instance here and there in which such has occurred among infants who were attended by medical men, but its incidence is almost invariably among those who were attended by nurses or professional midwives. It thus appears that some method in vogue among the latter, but not among the former, is probably the cause, and this $I$ believe is so, the direct reason being that the practice of midwives and nurses is to cut the cord too close to the abdominal wall. Having known the custom among a number of medical practitioners with regard to this point I can say that their habit is to divide the cord at from one and a half to two and a half inches from the umbilicus. With regard to the old order of nurses, I have personally been requested to cut it short as it saves trouble. The question then arises, Is it the practice amongst the present-day midwives to sever the cord closer to the abdominal wall than medical men, and, if so, is it done for the reason that it is best or satisfactory or for the reason of saving trouble? Before going further into this point it is necessary to consider something of the physiological process by which the aperture in the abdominal wall is closed and the umbilicus is formed. The latter is situated at the junction of the lower two-fifths and the upper three-fifths of the linea alba, and it is formed partly by the contraction of the fascia of the linea alba and partly by remnants of the funis. The centre of the umbilicus is said to be composed of the fibrous remains of the vessels, ${ }^{1}$ and it goes without saying that they are those that were in that portion of the funis left attached to the child's abdomen after its severance. The question then occurs, How much of the funis should be left in order that a firm and unyielding ambilicus may be found in the child?

On studying this question it seems that a different opinion is held by writers on midwifery and that their view differs somewhat from that which is the custom among practifioners. One well-known author states that the cord may be severed at $\frac{1}{2}$ or 1 inch from the umbilicus $;^{2}$ another says $1_{\frac{1}{2}}^{\frac{1}{2}}$ inches $;^{3}$ others say about $1 \frac{1}{2} .{ }^{4}$ While hesitating to question the opinion of any acknowledged authority on the subject of midwifery, I may be allowed to state that I believe the division as near the abdominal wall as $\frac{1}{2}$ or 1 inch is inadvisable and that its severance should be at a point of more than $1 \frac{1}{2}$ inches from the umbilicus rather than less, the best position being 2 to $2 \frac{1}{2}$ inches from the abdominal wall. That a portion of the funis is needed for the closure of the aperture is admitted, and I can account for the prevalence of umbilical hernia in infants in no other way than that the practice of midwives is to divide the cord too near the abdomen. If such is the case, there can be no satisfactory reason unless they have been instructed to do soand whether this is the case I am not in a position to say as if there were any additional trouble connected with the longer funis, such should not be considered when the danger of inducing a weakened condition of the abdominal wall is taken into account. Although it is the fact that such hernix as a rule tend to undergo cure the projection, which has been likened to the finger of a glove, would be far better prevented, and when it occurs may in some instances lead to umbilical hernia in late adult life, and in other cases cause a defect in the abdominal wall and thus tend to diminish the strength of an important structure of the body, and one on which the maintenance of the sound health of the individual is largely dependent. In conclusion,

I The Diseases of Children (Ashby and Wright), fifth edition, p. 165. 2 A Manual of Midwifery (Galabin).

The Science and Practice of Midwifery (Playfair) and Manual of Midwifers (Eden).
I may state that the condition of which I have written occurs among infants in whom none of the usual causes of acquired umbilical hernia are present, as phimosis or a narrow meatus.

Oxford, Jan. 5th, 1909.

I am, Sir, yours faithfully,

A. Stayt Dutrox.

\section{DRAINAGE IN CAIRO.}

\section{To the Editor of THE LANCET.}

SIR,-An idea is current in England that active drainage operations are in progress in Cairo and that there is there. fore much disturbance of soil and tearing up of the streets. Such is not the case; a main drainage scheme has been approved, but the work has not yet commenced nor will much be done for some time. The sewage farm in the desert will have to be done first. Cairo will not therefore be affected for probably some years. The principal hotels are all drained on the septic tank system and this has worked well. There need therefore be no fear that the health of Cairo has been altered by any drainage works. Diarrhcea is also supposed to be common amongst newcomers, but if greater precautions were taken to avoid chill to the abdomen, especially about sunset, this could largely be avoided. In addition to this I always advise my patients not to take green salad, as in any hot country raw vegetables are unsafe to eat.-I am, Sir, yours faithfully,

$$
\begin{aligned}
& \text { LLEWELLYN PHILliPs, M.D. Cantab., } \\
& \text { Cairo, Jan. 2nd, 1909. } \\
& \text { M.R.C.P. Lond., \&c. }
\end{aligned}
$$

\section{EPSOM COLLEGE.}

To the Editor of THE LAXCET.

SIR,-Like many others probably I have often been told that all medical men are gentlemen and rich, but experience teaches one that nearly all medical men not possessed of incomes other than professional are for their social position decidedly poor. Probably few, even at the top of the tree, after their expenses are deducted have a margin equal to that of a tolerably successful tradesman, whilst the incomes of the rank and file are being continually reduced by unfair hospital and club abuse, and the reduced incomes themselves are of less purchasing power owing to the continual rise in price of commodities and rates and taxes. I have for long maintained, like "Honorary Local Secretary" in THE LANCET of Jan. 9th, that the widows and orphans of medical men, if a charge upon anyone, should be maintained by the public, for whom the medical profession work night and day, often dying at their posts, for incomes which are absurdly below their deserts or even bookings. I should like to see hospital physicians and surgeons more careful in avoiding hospital abuse, and whenever opportunity offered putting in a word for the two medical charities-the British Medical Benevolent Fund and Epsom College. The former institution always appeals to my support in preference to the latter because the unfortunate applicants for relief are not put to the expense of canvassing for support. One is always pleased to see legacies of thousands of pounds left to hospitals for the benefit of the deserving poor, but I cannot help thinking that some of our leaders in the profession might secure legacies of substantial amounts for our medical charities. - I am, Sir, yours faithfally,

\section{A. Phillitps Hillis,}

Honorary Local Secretary, British Medical Battersea Park, S.W., Jan. 11th, 1909 Benevolent Fund.

\section{THE REMOVAL OF ERYTHEMA FROM THE FACE ("RED NOSE") BY THE PROLONGED INTERNAL AD- MINISTRATION OF ADRENALIN.}

\section{To the Editor of THE LANCET.}

SIR,-The fact that adrenalin is regarded as one of the strongest vaso-constrictors induced me to try its usefnlness by internal administration in cases of erythematous taches of the face ("red nose"). I have made observations on three cases ; two of them, demonstrated to the Kharkoff Dermatological Society in 1907, were students of the University, aged 